\title{
Postnatal Development of Glutamatergic, GABAergic, and Cholinergic Neurotransmitter Phenotypes in the Visual Cortex, Lateral Geniculate Nucleus, Pulvinar, and Superior Colliculus in Cats
}

\author{
Viggo M. Fosse, ${ }^{\text {a }}$ Paul Heggelund, ${ }^{1}$ and Frode Fonnum \\ Norwegian Defence Research Establishment, Division of Environmental Toxicology, N-2007 Kjeller, Norway, and \\ University of Oslo, Institute of Neurophysiology, N-0162 Oslo 1, Norway
}

We have analyzed the postnatal development of glutamatergic/aspartergic, GABAergic, and cholinergic neurotransmitter systems in the visual cortical Areas 17 and 18, lateral geniculate nucleus (LGN), pulvinar, and the visual and nonvisual parts of superior colliculus (SC) in kittens. High-affinity uptake of D-aspartate (HA D-Asp), glutamate decarboxylase (GAD), and choline acetyltransferase (ChAT) activities were measured as a means of probing the development of the respective transmitter systems.

HA D-Asp exceeded the adult level several-fold in all areas during the postnatal period which corresponded with the period of maximal dendritic/axonal branching patterns and synapse densities in the respective regions. GAD exhibited a gradual increase towards adult levels during the first month. The adult level was reached during postnatal week (PNW) 5-6 in Areas 17 and 18, during PNW3 within LGN, pulvinar, and the visual part of SC. In the nonvisual part of SC, the adult GAD level was reached as early as PNW2. ChAT exhibited biphasic developmental profiles in Areas 17 and 18. An initial peak of near adultlike activity in PNW2 was followed by a decline and subsequently by a slow increase towards adult levels during PNW5-17. ChAT developed very slowly in LGN and pulvinar, and in the latter structure only $\sim 70 \%$ of the adult activity had been attained by PNW17. In both subdivisions of SC, ChAT had reached adult levels during PNW3-5.

Dark-rearing from birth until PNW6 moderately attenuated GAD development in all areas and increased ChAT activity in Areas 17 and 18 but did not affect development of HA $\mathrm{D}$-Asp in any part of the kitten visual system.

Our neurochemical findings in the developing cat visual system are consistent with available evidence regarding 10calization of neurotransmitter systems, as well as postnatal changes in terms of cytoarchitectonics, synaptogenesis, functional development, and susceptibility to neonatal darkrearing in visual pathways.

\footnotetext{
Received Feb. 15, 1988; revised June 29, 1988; accepted July 6, 1988.

We greatly appreciate the very skillful, enthusiastic, and enduring assistance of Mrs. Evy Grini Iversen.

" Correspondence should be addressed to V. M. Fosse at his present address: National Veterinary Institute, Department of Animal Genetics, P.O. Box 8156 Dep., N-0033 Oslo 1, Norway.

Copyright (C) 1989 Society for Neuroscience $0270-6474 / 89 / 020426-10 \$ 02.00 / 0$
}

All the main visual centers and their afferent/efferent connections have been formed by the end of the fetal period in most mammals, but their functional connectivity has not yet been established. Thus, during the early postnatal period various subsets of the visual system mature by going through structural, neurochemical, and functional developmental changes. Each neurotransmitter phenotype matures by acquiring the capability of neurotransmitter synthesis, storage, release, and transmitter inactivation (e.g., by re-uptake and/or degradation). Synaptogenesis is also accompanied by the expression of appropriate receptor functions on the pre- and postsynaptic elements. Previously, a series of investigations was conducted to compare neurochemical development with relevant anatomical and electrophysiological changes in visual areas in the rat (e.g., McDonald et al., 1981; Kvale et al., 1983; Fosse et al., 1984b) and the cat (e.g., Potempska et al., 1979; Shaw et al., 1984, 1985, 1986).

Different functions in visual pathways have been linked to distinct morphological units (Gilbert and Wiesel, 1979; Sillito and Kemp, 1983a, b; Parnavelas, 1984; Sillito, 1984), and postnatal changes in visual function and cytoarchitectonics have been described in several species. Analysis of the postnatal development of neurotransmitter parameters as an adjunct to knowledge regarding anatomical and functional ontogeny may thus enable identification of specific neuronal subsets and neurotransmitter systems to serve specific functions.

It is also known that environmental factors, e.g., visual deprivation, may influence the functional and morphological development in the visual system (see Wiesel, 1982). In kittens there is a critical period between 1 and 3 months after birth during which the developing visual cortex is particularly sensitive to environmental manipulations (Wiesel, 1982). It has been demonstrated that dark-rearing of neonatal kittens may delay the critical period of cortical plasticity (Cynader and Mitchell, 1980).

The widespread use and seemingly great functional importance of neuronal systems incorporating glutamate/aspartate (Glu/Asp), GABA, and ACh as neurotransmitters in visual pathways (Sillito and Kemp, 1983a, b; Fonnum, 1984; Fonnum et al., 1984a; Houser et al., 1984; Streit, 1984) prompted us to analyze their postnatal development in various subdivisions of the cat visual system. In addition, we have quantitated the neurochemical effects of dark-rearing kittens from birth until PNW6. High-affinity (HA) uptake of D-Asp was used as the main marker of Glu/Asp neurons and terminals (Fonnum et al., 1980; Fonnum and Malthe-Serenssen, 1981). Since the pharmacological 


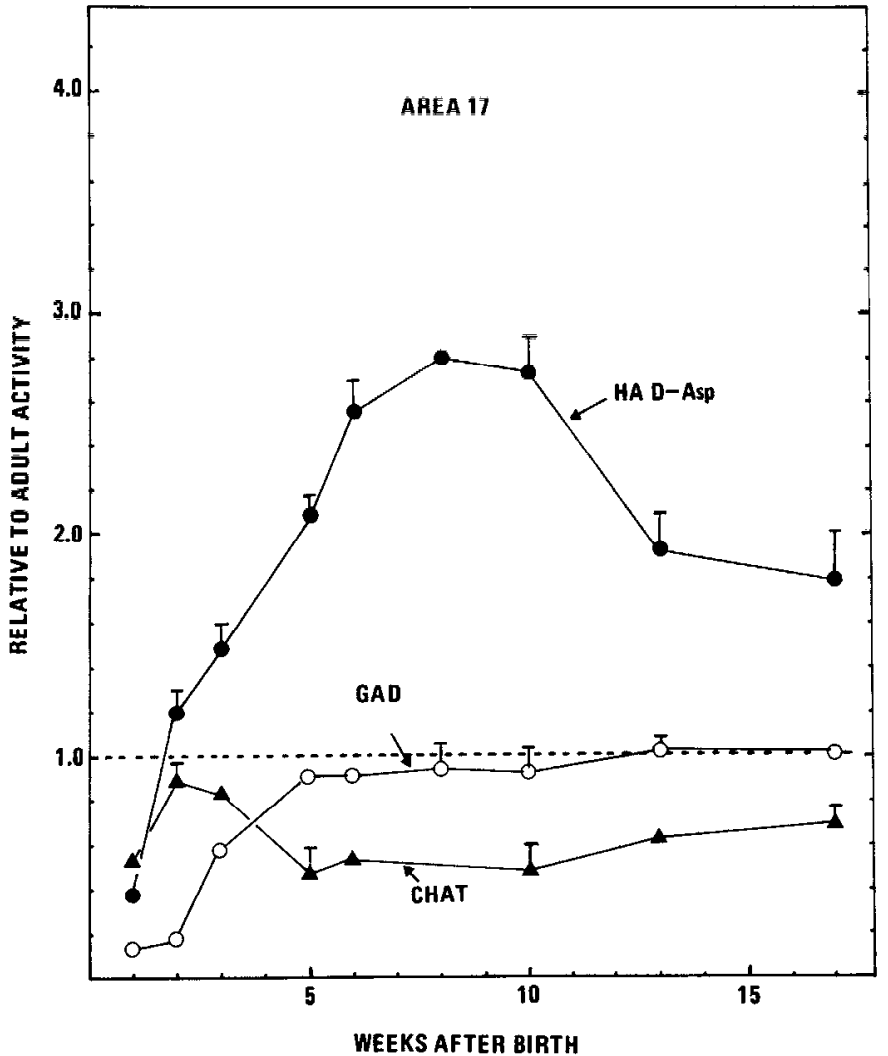

Figure 1. Postnatal developmental profiles of high-affinity uptake of D- ${ }^{3} \mathrm{H}$-aspartate (HA D-Asp), glutamate decarboxylase (GAD), and choline acetyltransferase (ChAT) in Arca 17 of cats. Each point on the curves represents the relative activity (mean \pm SEM) compared with that observed for the respective parameters in adults. The number of adult cats was 8 , and 4-6 kittens were used at each developmental stage. The neurochemical measurements were conducted as described in $\mathrm{Ma}$ terials and Methods. Adult activities ( $\mu$ mol gm protein $\left.{ }^{-1} \mathrm{hr}^{-1}\right)$ of the respective markers were $0.25 \pm 0.02$ (HA D-Asp), $82.1 \pm 3.8$ (GAD), and $8.7 \pm 0.8$ (ChAT) (means $\pm \mathrm{SEM}, n=8$ ). Broken line depicts the level of adult activity for all parameters, and the SEMs at each stage are indicated by vertical bars.

properties of Glu and Asp overlap and are still elusive (Foster and Fagg, 1984; Fagg et al., 1986), we prefer to use the term Glu/Asp-ergic to describe the neurotransmitter phenotype of neurons using either or both as transmitter. The enzymes glutamic acid decarboxylase (GAD) and choline acetyltransferase (ChAT) were used as markers of GABAergic and cholinergic neurons, respectively. These methods are considered as rational markers for the respective neurotransmitter phenotypes (StormMathisen, 1977; Fonnum, 1984) and hence as means to monitor their development.

\section{Materials and Methods}

A total of 31 kittens and 12 adult cats were used. The number of kittens used at each developmental stage ranged from 2 to 6 , and samples from each hemisphere were treated as independent entities for the statistical computations. Areas 17-19 (Brodmann, 1905) were aspirated in 3 kittens during the 4th postnatal week essentially as described previously (Kvale et al., 1983; Fosse et al., 1984a), and the operated kittens were sacrificed 10-12 d later. During surgery they were anesthetized with pentobarbital $(30 \mathrm{mg} / \mathrm{kg}$, i.p.). Another 3 kittens were raised in total darkness (i.e., dark-reared) from birth until they were sacrificed at the end of the 6th postnatal week. All cats/kittens were killed by a lethal dose of pentobarbital $(60 \mathrm{mg} / \mathrm{kg}$, i.p.). Separate experiments with rats have demonstrated that this dose of pentobarbital affects the neuro-

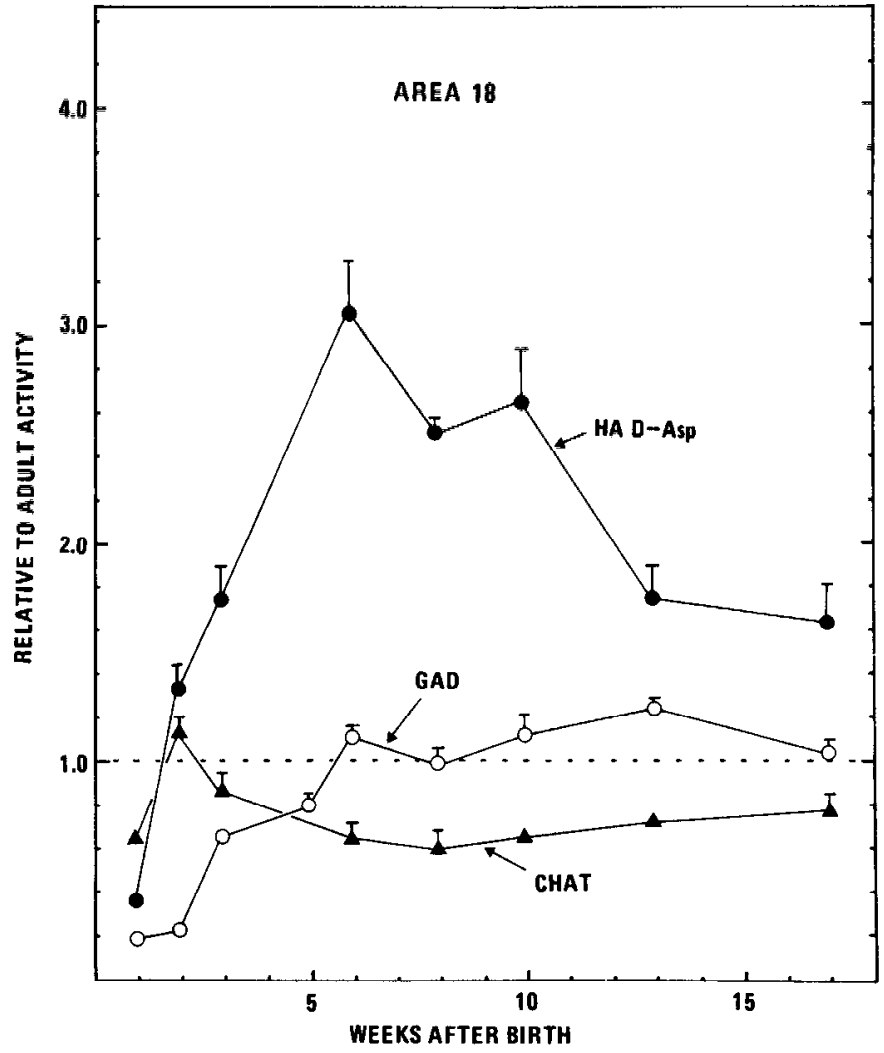

Figure 2. Postnatal developmental profiles of high-affinity uptake of $\mathrm{D}^{-}{ }^{3} \mathrm{H}$-aspartate (HA D-Asp), glutamate decarboxylase (GAD), and choline acetyltransferase (ChAT) in Area 18 of cats. Adult activities $(\mu \mathrm{mol} \mathrm{gm}$ protein $^{-1} \mathrm{hr}^{-1}$ ) for the respective markers were $0.25 \pm 0.03$ (HA D-Asp), $76.1 \pm 3.3$ (GAD), and $8.8 \pm 0.4(\mathrm{ChAT})$ (means $\pm \mathrm{SEM}, n$ $=8$ ). See legend to Figure 1 and Materials and Methods for other details.

chemical parameters (e.g., uptake) minimally and to the same extent in neonates and adults (V. M. Fosse, unpublished observations).

Preparation of brain tissue. The various visual areas were dissected as described previously (Fosse et al., 1984a) according to the cat brain atlas of Reinoso-Suarez (1961). Tissue samples to be used in the uptake and radioenzymatic assays were homogenized in $0.32 \mathrm{M}$ sucrose, $\mathrm{pH}$ 7.4 , in Teflon/glass homogenizers (10 strokes/900 rpm). HA uptake of $\mathrm{D}^{-3} \mathrm{H}$-Asp was measured within $30 \mathrm{~min}$ after homogenization. Subsequently, Triton X-100 was added to each homogenate (final concentration, $0.2 \%$ ) to release occluded/bound enzymes (GAD and ChAT).

Biochemical methods. The analysis of HA D- ${ }^{3} \mathrm{H}-$ Asp uptake, GAD and ChAT activities, and the protein measurements were conducted by established procedures (Fosse et al., 1984a, 1986). Studies on the inhibition by SITS of $\mathrm{HA} \mathrm{D}^{-}{ }^{3} \mathrm{H}$-Asp uptake were performed according to Waniewski and Martin (1983) with homogenates prepared from two 6 -week-old kittens ( $n=4$ hemispheres) and 2 adult cats ( $n=4$ hemispheres).

Materials. $\mathrm{D}^{-3} \mathrm{H}$-Aspartic acid and $\mathrm{L}-{ }^{3} \mathrm{H}$-glutamic acid were purchased from New England Nuclear, $1-{ }^{14} \mathrm{C}$-acetyl-CoA and $1-{ }^{14} \mathrm{C}$-glutamic acid from Amersham, and SITS from BDH (Poole, England). All other chemicals were of the highest purity available from commercial sources.

\section{Results}

\section{Glu/Asp-ergic systems}

In both Areas 17 and 18, HA D-Asp uptake reached adult activity between PNW1 and 2 (Figs. 1, 2). During the period PNW6-8 the uptake activity in Areas 17 and 18 reached peak values that exceeded the adult level by a factor of $\sim 3$. By PNW 17, the HA D-Asp uptake activity had decreased but was still $80 \%$ above the respective levels in adult cats.

In LGN and pulvinar HA D-Asp uptake increased more slowly 


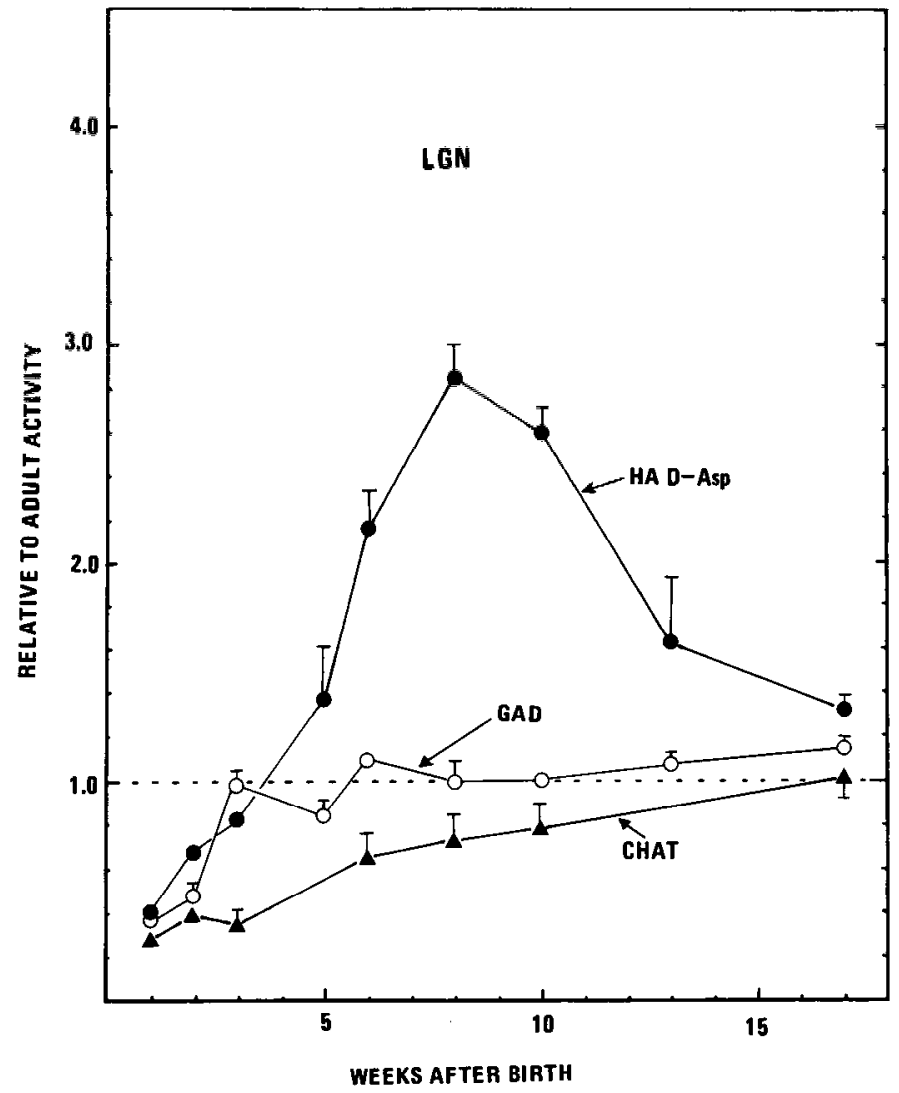

Figure 3. Postnatal developmental profiles of high-affinity uptake of $\mathrm{D}^{-3} \mathrm{H}$-aspartate (HA D-Asp), glutamate decarboxylase (GAD), and choline acetyltransferase (ChAT) in the lateral geniculate nucleus (LGN) of cats. Adult activities ( $\mu \mathrm{mol} \mathrm{gm}$ protein ${ }^{-1} \mathrm{hr}^{-1}$ ) for the respective markers were $0.33 \pm 0.02$ (HA D-Asp), $88.1 \pm 5.3$ (GAD), and $25.5 \pm 2.5$ (ChAT) (means \pm SEM, $n=8$ ). See legend to Figure 1 and Materials and Methods for other details.

than in the visual cortical areas. The adult level was reached during PNW3-4 in both structures (Figs. 3, 4), and the uptake activities were maximal in PNW8. At that time the activities were $\sim 2.8$ and $\sim 2.4$ times higher than the adult levels in LGN and pulvinar, respectively. Subsequently, the uptake activity subsided but had not attained the adult level in either structure by PNW17.

Immediately after birth (PNW1) HA D-Asp uptake in the visual and nonvisual parts of $\mathrm{SC}$ exceeded their respective adult levels. In the visual part (Fig. 5), the uptake activity was nearly twice the adult level in PNW1. The peak of uptake activity, which was reached in PNW3, exceeded the adult level by a factor of 4.5. Developmental profiles of HA D-Asp uptake were quite similar in the visual and nonvisual parts of SC. However, in the nonvisual part the uptake activity was nearly 3 times greater than the adult level in PNW1, whereas the peak in PNW 3 was $\sim 5.6$ times greater (Fig. 6). The subsequent decrease was slower in the nonvisual than in the visual part of SC. Nevertheless, in PNW13 and 17 the relative uptake activities were similar in the 2 subdivisions and only marginally above their respective adult levels (Figs. 5, 6).

SITS (4-acetamido-4'-isothiocyanostilbene-2,2'-disulfonic acid) inhibits the glial transporter of acidic amino acids (e.g., Glu) and exhibits an $\mathrm{IC}_{50}$ of $\sim 20$ and $\sim 80 \mu \mathrm{M}$ with glioma and astrocyte cells, respectively (Waniewski and Martin, 1983). The substance is a much less potent inhibitor of Glu uptake into

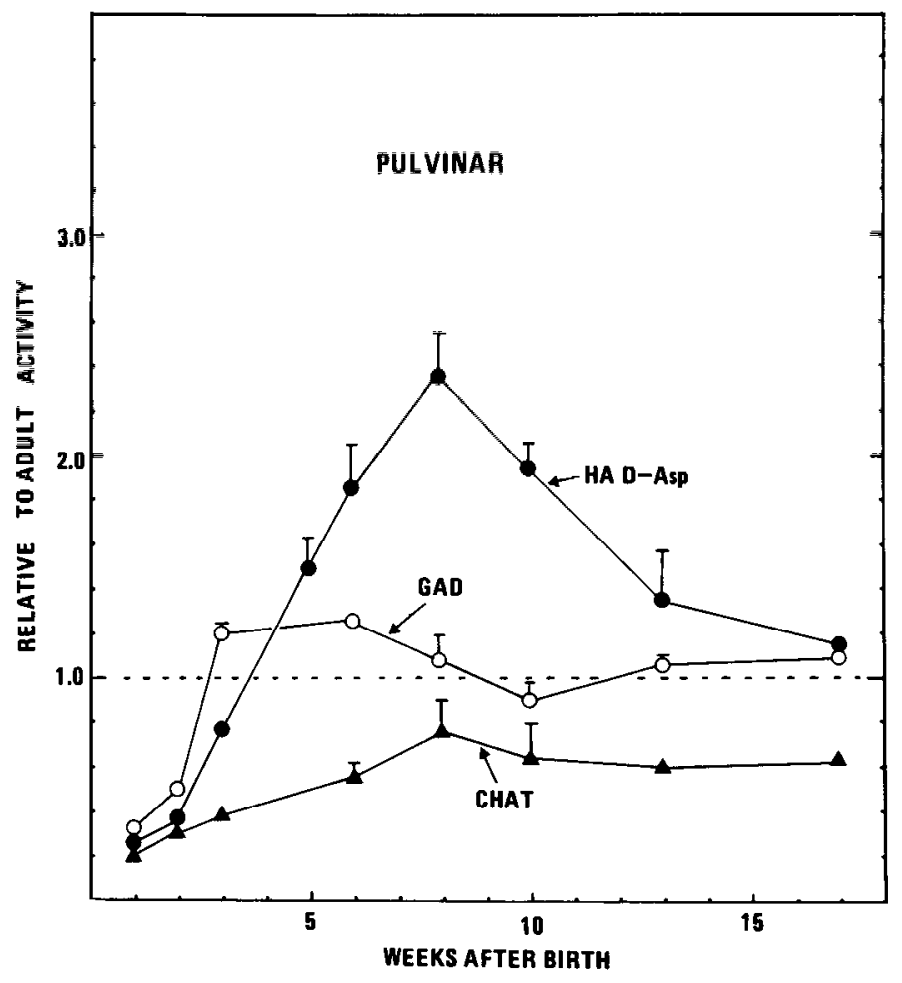

Figure 4. Postnatal developmental profiles of high-affinity uptake of D- ${ }^{3} \mathrm{H}$-aspartate (HA D-Asp), glutamate decarboxylase (GAD), and choline acetyltransferase (ChAT) in the pulvinar of cats. Adult activities $\left(\mu \mathrm{mol} \mathrm{gm} \mathrm{protein}^{-1} \mathrm{hr}^{-1}\right.$ ) for the respective markers were $0.61 \pm 0.05$ (HA D-Asp), $65.0 \pm 2.7$ (GAD), and 14.7 (ChAT) (means \pm SEM, $n$ $=8$ ). See legend to Figure $l$ and Materials and Methods for other details.

purified synaptosomes with which the IC $_{50}$ of SITS was $\sim 1900$ $\mu \mathrm{M}$ (Waniewski and Martin, 1983). In homogenates of rat visual cortex, the $\mathrm{IC}_{50}$ of SITS for D-Asp and L-Glu uptake is $\sim 1600$ $\mu \mathrm{M}$ (V. M. Fosse, unpublished observations). These properties of SITS were exploited to monitor the glial component in the neonatal exuberance of HA D-Asp uptake. We found that the $\mathrm{IC}_{50}$ of SITS was very similar in all of the visual structures and that it did not differ significantly between neonatal and adult cats, i.e., $\sim 1000 \mu \mathrm{M}$ in the PNW6 kittens and $\sim 1300 \mu \mathrm{M}$ in the adults.

Visual cortex (Areas 17-19) was ablated in neonatal kittens during PNW4 as another experimental approach to enable identification of elements responsible for the neonatal exuberance of HA D-Asp uptake activity. We found that 10-12 d after the cortical lesion HA D-Asp uptake had decreased significantly in the deafferented LGN $(-47 \%)$, pulvinar $(-46 \%)$, visual part of SC $(-28 \%)$, and also in the nonvisual part of SC $(-16 \%)$ compared with the respective uptake activities in the contralateral nondeafferented areas (Table 1).

\section{GABAergic systems}

GAD activity had reached only $15-20 \%$ of the adult level in Area 17 during the first 2 postnatal weeks (Fig. 1). The adult level of GAD activity was attained in PNW5 and remained at this level throughout the rest of the observation period. The developmental profile of GAD in Area 18 (Fig. 2) was quite similar to that observed in Area 17.

In the period PNW 1-3 GAD activity in LGN increased from $40 \%$ to near adult level and exhibited only minor fluctuations around this value until PNW 17 (Fig. 3). In the adjacent pulvinar, 


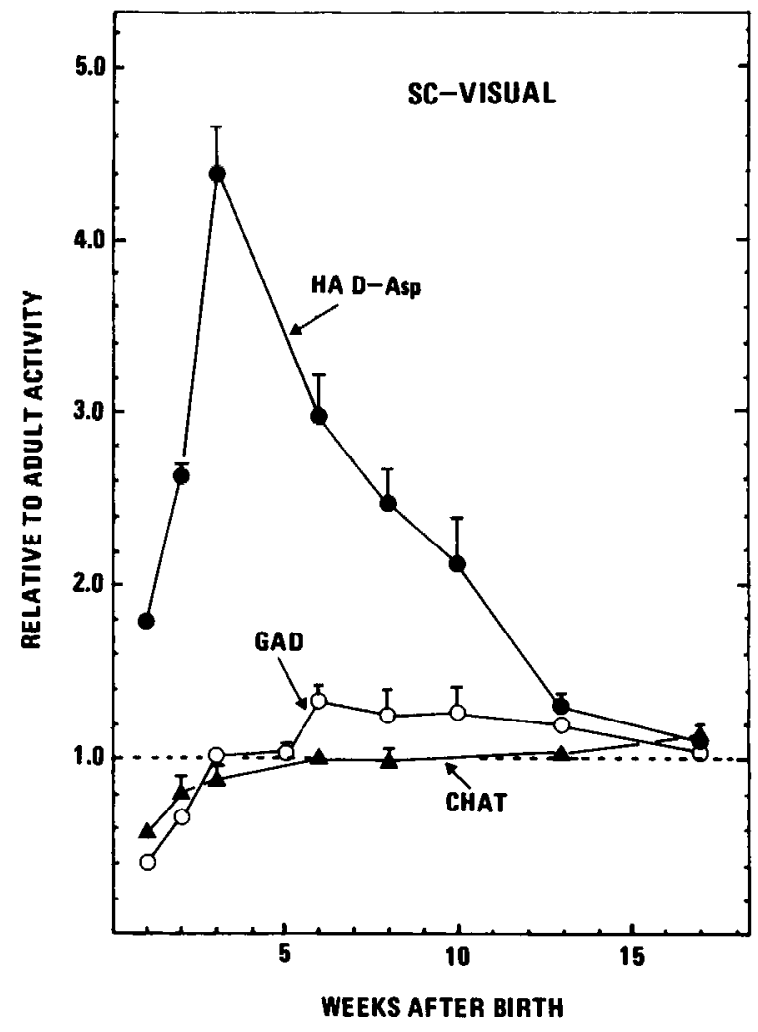

Figure 5. Postnatal developmental profiles of high-affinity uptake of D- ${ }^{3} \mathrm{H}$-aspartate (HA D-Asp), glutamate decarboxylase (GAD), and choline acetyltransferase (ChAT) in the visual part of superior colliculus (SC-visual) in cats. Adult activities ( $\mu \mathrm{mol} \mathrm{gm} \mathrm{protein}{ }^{-1} \mathrm{hr}^{-1}$ ) for the neurochemical markers were $0.14 \pm 0.01$ (HA D-Asp), $157 \pm 6$ (GAD), and $24.5 \pm 1.4$ (ChAT) (means $\pm \mathrm{SEM}, n=8$ ). See legend to Figure 1 and Materials and Methods for other details.

GAD reached the adult level at the same time as in LGN but exceeded this level by $20-30 \%$ in the period PNW3-6 (Fig. 4).

The GAD activity in the visual part of SC was $40 \%$ of the adult level in PNW1, and fully developed activity was reached in PNW3 (Fig. 5). Immediately after birth, GAD was more developed in the nonvisual (Fig. 6) than in the visual part of SC. In PNW1, GAD activity had already reached $80 \%$ of the adult level, and the latter was attained in PNW2. In both parts of SC there was a small overshoot of GAD activity between PNW5 and 15 (Figs. 5, 6).

\section{Cholinergic systems}

ChAT activity exhibited a biphasic developmental profile in both Areas 17 and 18 (Figs. 1, 2). In Area 17 the activity was $\sim 50 \%$ of the adult level in PNW1 and reached a transient peak in PNW2 that was very close to the adult ChAT level (Fig. 1). Subsequently, ChAT activity subsided to $50 \%$ of adult level in PNW5. Thereafter, the activity increased again at a slow rate and had reached $80 \%$ of the adult level in PNW17 (Fig. 1). ChAT activity in Area 18 (Fig. 2) was 10-15\% higher than in Area 17 at all stages throughout the observation period.

A very protracted developmental profile of ChAT activity was observed in LGN (Fig. 3). It increased gradually from 30\% (in PNW1) to full maturation in PNW17. In pulvinar, ChAT showed an even slower rate of development than observed in LGN, being only $20 \%$ of the adult level in PNW1 and $\sim 70 \%$ of the adult level by PNW17 (Fig. 4).

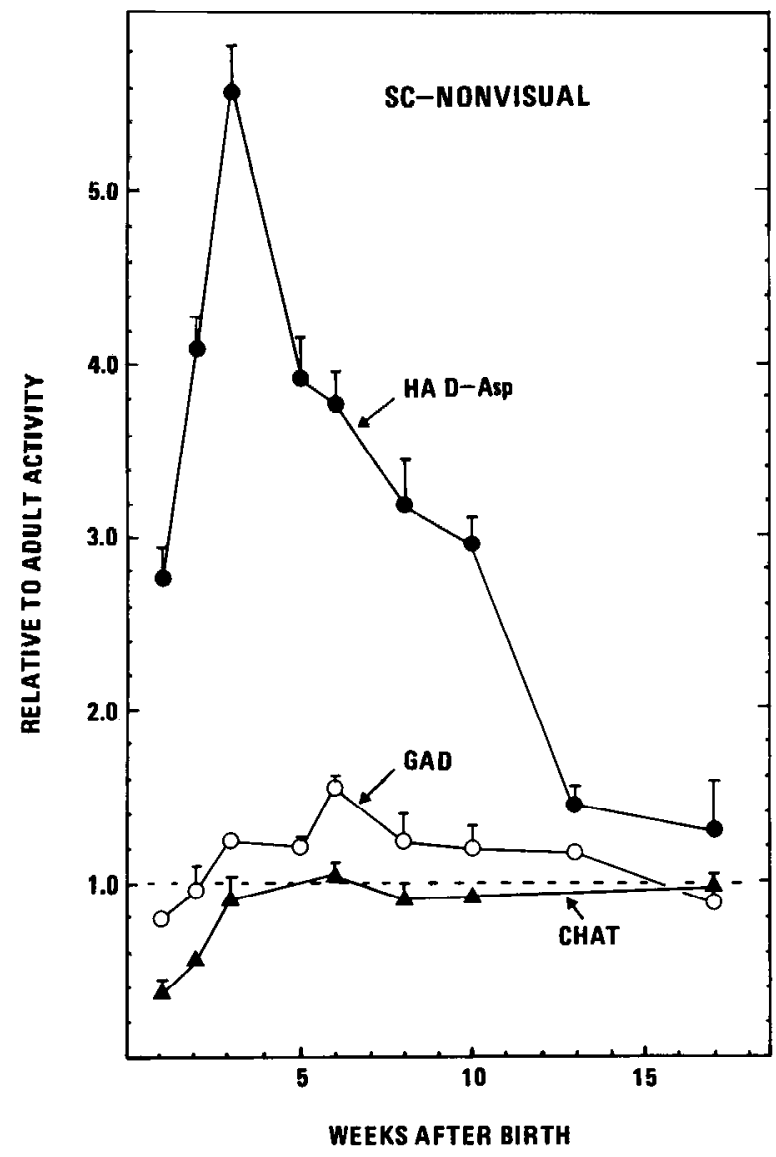

Figure 6. Postnatal developmental profiles of high-affinity uptake of D- ${ }^{3} \mathrm{H}$-aspartate (HA D-Asp), glutamate decarboxylase (GAD), and choline acetyltransferase (ChAT) in the nonvisual part of superior colliculus (SC-nonvisual) in cats. Adult activities ( $\mu \mathrm{mol} \mathrm{gm} \mathrm{protein}{ }^{-1} \mathrm{hr}^{-1}$ ) for the neurochemical markers were $0.11 \pm 0.01$ (HA D-Asp), $97 \pm 6$ (GAD), and $15.7 \pm 0.8(\mathrm{ChAT})$ (means $\pm \mathrm{SEM}, n=8)$. See legend to Figure 1 and Materials and Methods for other details.

ChAT activity in the visual part of SC was $60 \%$ of the adult level in PNW1. The adult level of activity was attained in PNW3 (Fig. 5). During the first 2 weeks after birth, ChAT was less developed in the nonvisual (Fig. 6) than in the visual part of SC. However, ChAT activity reached full maturity at about the

Table 1. Effects of Area 17/18 ablation on high-affinity uptake of D-3-aspartate in subcortical visual areas in 6-week-old kitten

\begin{tabular}{lcll} 
Visual area & $\begin{array}{c}\text { Nonoperated } \\
\text { (control) side }\end{array}$ & Operated side & $\begin{array}{l}\% \\
\text { Change }\end{array}$ \\
\hline Area 17 & $646 \pm 21$ & - & - \\
Area 18 & $684 \pm 22$ & - & - \\
LGN & $689 \pm 63$ & $365 \pm 52^{*}$ & -47 \\
Pulvinar & $1001 \pm 68$ & $539 \pm 34^{*}$ & -46 \\
Superior colliculus & & & \\
$\quad$ Visual part & $387 \pm 39$ & $280 \pm 7 \dagger$ & -28 \\
$\quad$ Nonvisual part & $383 \pm 27$ & $308 \pm 14 \dagger$ & -19 \\
\hline
\end{tabular}

The visual cortex (Areas 17-19) was ablated unilaterally in 3 kittens in the 4th postnatal week. After 10 d survival time, the kittens were killed with an overdose of pentobarbital $(60 \mathrm{mg} / \mathrm{kg})$ and $\mathrm{D}^{3} \mathrm{H}$-Asp uptake was measured in homogenate prepared from the respective areas in the nonoperated and operated hemispheres. Results are presented as nmol/gm protein/hr (mean \pm SD). Differences between operated and nonoperated sides: ${ }^{*} p<0.005$ and $\dagger p<0.01$ (Student's $t$ test). The percentage change denotes the reduction in uptake on the operated side as compared with the nonoperated side. 
430 Fosse et al. - Neurochemical Development in the Cat Visual System

Table 2. Effects of dark-rearing on neurochemical development in the neonatal cat visual system

\begin{tabular}{|c|c|c|c|c|c|c|}
\hline \multirow[b]{2}{*}{ Area } & \multicolumn{2}{|l|}{ HA D-Asp uptake } & \multicolumn{2}{|l|}{$\mathrm{GAD}$} & \multicolumn{2}{|l|}{ ChAT } \\
\hline & Normally reared & Dark-reared & Normally reared & Dark-reared & Normally reared & Dark-reared \\
\hline Area 17 & $0.65 \pm 0.02$ & $0.65 \pm 0.07$ & $81.4 \pm 1.6$ & $74.4 \pm 2.5 \dagger$ & $4.9 \pm 0.2$ & $6.3 \pm 0.5^{*}$ \\
\hline Area 18 & $0.68 \pm 0.02$ & $0.63 \pm 0.02$ & $83.2 \pm 2.2$ & $70.2 \pm 2.1^{*}$ & $5.5 \pm 0.2$ & $6.4 \pm 0.5 \dagger$ \\
\hline LGN & $0.69 \pm 0.06$ & $0.60 \pm 0.10$ & $97.4 \pm 2.2$ & $75.0 \pm 1.6^{*}$ & $19.2 \pm 1.7$ & $22.0 \pm 1.6$ \\
\hline Pulvinar & $1.00 \pm 0.07$ & $1.06 \pm 0.06$ & $83.6 \pm 2.4$ & $57.6 \pm 2.4^{*}$ & $7.7 \pm 0.6$ & $6.9 \pm 1.1$ \\
\hline \multicolumn{7}{|l|}{$\mathrm{SC}$} \\
\hline Visual part & $0.39 \pm 0.04$ & $0.32 \pm 0.04$ & $207 \pm 12$ & $186 \pm 4 \dagger$ & $24.0 \pm 0.9$ & $26.0 \pm 3.7$ \\
\hline Nonvisual part & $0.38 \pm 0.03$ & $0.31 \pm 0.02$ & $152 \pm 5$ & $115 \pm 3^{*}$ & $17.2 \pm 0.9$ & $17.3 \pm 1.6$ \\
\hline
\end{tabular}

Two kittens ( $n=4$ hemispheres) were dark-reared from birth until the 6 th postnatal week, at which time they were killed by a lethal dose of pentobarbital (60 mg $/ \mathrm{kg}$ ) Tissue samples were dissected from visual cortex (Areas 17 and 18), visual thalamus [lateral geniculate nucleus (LGN) and pulvinar] and the visual and nonvisual parts of superior colliculus (SC). Measurements of high-affinity uptake of ${ }^{-}{ }^{3} \mathrm{H}-\mathrm{Asp}$ (HA D-Asp uptake), glutamate decarboxylase (GAD), and choline acetyltransferase (ChAT) were performed as described in Materials and Methods. Results were compared with those obtained from respective areas in 3 kittens ( $n=6$ hemispheres) of the same age raised concurrently with normal visual experience. All results are expressed as $\mu \mathrm{mol} / \mathrm{gm}$ protein $/ \mathrm{hr}$ (means \pm SEM). Differences between dark-reared and normally reared kittens: ${ }^{*} p<0.01$ and $\dagger p<0.05$ (Student's $t$ test).

same time in both parts of SC, i.c., during the period PNW35 (Figs. 3-5).

\section{Effects of dark-rearing on neurochemical development}

Three kittens were reared in total darkness from birth until PNW6. The HA D-Asp uptake, GAD, and ChAT activities in the visual areas of the dark-reared kittens were compared with those in 3 kittens of the same age that had been reared with normal visual experience. We found that HA uptake of $\mathrm{D}-\Lambda \mathrm{sp}$ was not affected in any of the areas under study after darkrearing, whereas GAD activity decreased in all areas (Table 2), the largest decrease being in the visual thalamus $(20-30 \%$ reduction) and the least in Area 17 and the visual part of SC $(\sim 10 \%$ reduction). ChAT activity was increased in Area 17 $(+28 \%)$ and Area $18(+16 \%)$, whereas the small changes observed in the other areas were not statistically significant (Table 2).

\section{Discussion}

\section{Glu/Asp-ergic systems}

The sites for HA D-Asp uptake are primarily localized at Glu/ Asp-ergic synapses on the nerve terminal and adjacent astrocytes (Fonnum et al., 1980; Fonnum, 1984) and are probably identical to the Na-dependent Glu-binding sites (Fonnum et al., 1980; Vincent and McGeer, 1980). HA D-Asp uptake has appeared to be a rational marker for Glu/Asp-ergic neurons/terminals (Fonnum and Malthe-Sørenssen, 1981) and is reduced in projection areas after defined lesions of suspected Glu/Aspergic pathways (see Fonnum, 1984). It has also been shown that developing neuronal growth cones are richly endowed with uptake sites for appropriate ncurotransmitters (Gordon-Wecks et al., 1984). Therefore, HA D-Asp uptake activity may be expected to change in concert with and reflect the degree of axonal/dendritic branching and density of excitatory Glu/Asp-ergic growth cones and synapses. In all visual areas we found that SITS, a presumed inhibitor of the glial uptake of acidic amino acids (Waniewski and Martin, 1983), was equipotent as inhibitor of HA D-Asp uptake in homogenates of the visual areas in PNW6 kittens and adult cats (see Results). Furthermore, the exuberant uptake was reduced significantly in subcortical visual centers after ablation of Areas 17-19 in neonatal kittens (Table 1). The excess HA D-Asp uptake activity in the neonatal period (Figs.
1-6) was paralleled by a similar exuberance of $\mathrm{Na}$-dependent Glu-binding sites (V. M. Fosse, unpublished observations). Thus, we conclude that the predominant part of the HA D-Asp uptake in homogenates of the developing visual areas in kitten brain represents uptake into terminals and growth cones.

\section{Areas 17 and 18}

In the developing kitten and primate visual cortex there is an initial rapid increase in excitatory synapse density which eventually exceeds the adult level. In kittens the peak of synapse density occurs during PNW5-8 (Cragg, 1975; Winfield, 1981). The exuberant synapses are subsequently decreased in number and their density subsides towards adult levels late in the postnatal period. Relative to adult levels the presumed excitatory Type I synapses are more exuberant than the inhibitory Type II synapses (Mates and Lund, 1983a, b). Our finding that HA uptake of $\mathrm{D}$-Asp in the visual cortical areas also exhibits the maximal activity at about the same time suggests that a major fraction of the Type I synapses reflect density of excitatory (e.g., Glu/Asp-ergic) terminals and synapses during development. Most likely the changes in HA D-Asp uptake represent the development/synaptogenesis of Glu/Asp-ergic intrinsic neurons (Streit, 1984), geniculocortical afferents (Tsumoto et al., 1986), and collaterals of the pyramidal neurons (Gilbert and Wiesel, 1979; Baughman and Gilbert, 1981).

In the kitten visual cortex local neurons exhibit extensive axonal and dendritic arborizations during postnatal development that are subsequently "pruned" to attain their respective adult morphologies (Meyer and Ferres-Torres, 1984). Interestingly, many of these neurons have their most elaborate branching patterns during the period that encompasses maximal uptake activity and synapse density.

\section{$L G N$ and pulvinar}

The cortical afferents have reached the visual thalamus at the time of birth in kittens (Anker, 1977), but their terminal arbors and the dendrites on which they impinge remain relatively immature until PNW2-3 (Mason, 1983). After that time they are subject to a maturation process encompassing extensive terminal and dendritic elaborations that are maximally developed during PNW4-6 (Mason, 1983). Subsequently, the neuronal morphology attains adult characteristics in the late postnatal period (Mason, 1983). These changes are comparable to the 
developmental profiles of Type I (asymmetric) synapses in the neuropil of LGN (Cragg, 1975; Winfield et al., 1976) and the postnatal changes of $\mathrm{H} \Lambda \mathrm{D}-\Lambda \mathrm{sp}$ uptake in LGN and pulvinar (Figs. 3, 4). In both structures, the changes in HA D-Asp uptake probably reflect development of terminal/dendritic arborizations and synapse density of the afferent Glu/Asp-ergic terminals which are mainly of visual cortical origin (Lund Karlsen and Fonnum, 1978; Baughman and Gilbert, 1981; Kvale et al., 1983; Fosse et al., 1984a, b, 1986; Fosse and Fonnum, 1987).

Very little is known about the morphological and functional development of pulvinar. It is therefore difficult to discuss biochemical findings in relation to postnatal development in this structure. However, according to available histochemical and morphological evidence (Eitschberger, 1970; Zilles, 1978; Ogren and Rakic, 1981), it may be assumed that the 2 juxtaposed thalamic nuclei (LGN and pulvinar) share many features regarding their postnatal neurochemical ontogeny. These assumptions are supported by similarities in anatomical organization (Jones, 1983) and neurotransmitter systems (Fosse et al., 1984a, 1986; Fosse and Fonnum, 1987), and also by the fact that the developmental profiles of Glu/Asp-ergic, GABAergic, and cholinergic parameters are nearly congruous in the 2 nuclei (Figs. 3, 4).

\section{Superior colliculus}

The early appearance of IIA D-Asp uptake in excess of adult values probably represented uptake into terminals of the local Glu/Asp-ergic neurons (Kvale et al., 1983; Fosse et al., 1986; Fosse and Fonnum, 1986). However, the subsequent increase to a considerable peak during PNW 1-3 was most likely due to axonal arborization and synapse formation of the extrinsic Glu/ Asp-ergic elements (Mathers, 1977; Mathers et al., 1978; Stein and Gallagher, 1981; Kvale et al., 1983; Fosse et al., 1984b). Although the density of the Glu/Asp innervation is higher in the visual than in the nonvisual part of SC (Fosse et al., 1984a; Greenamayre et al., 1984), the latter matures slightly earlier and exhibits a more profound exuberance of HA D-Asp uptake (Figs. $5,6)$. This is consistent with the cellular and synaptic development within SC (Brückner et al., 1976; Labriola and Laemle, 1977; Mathers et al., 1978; Mustari et al., 1979). We also found evidence for a transient visual cortical Glu/Asp-ergic innervation of the nonvisual laycrs of SC (Table 1) as judged by the slight but significant decrease of HA D-Asp uptake after ablation of Areas 17-19 during PNW4-6. In adult cats, this was not the case (Fosse et al., 1984a), but only Area 17 was ablated in that study.

\section{Possible functions of HA uptake systems during development}

Early development and exuberance of HA uptake of neurotransmitters during postnatal development have been demonstrated for Glu/Asp-ergic (Hitzemann and Loh, 1978; Kvale et al., 1983; Sandoval et al., 1984), GABAergic (Coyle and Enna, 1976; Redburn et al., 1978; Kvale et al., 1983), cholinergic (Bader et al., 1978; Thompson, 1982), and aminergic systems (Jonsson and Kasamatsu, 1983). Our findings in this study indicate that HA D-Asp uptake changes in concert with axonal/dendritic arborizations and the formation of Type I synapses. During nervous system development there is evidence that neurotransmitters and nerve activity may serve epigenetic functions, e.g., by promoting or inhibiting synaptogenesis (Wolff, 1979; Haydon et al., 1984; Dames et al., 1985; Kalil et al., 1986) and by influencing expression of receptor functions (Ferrero et al., 1984).
Interestingly, it was recently shown that Glu may promote neurite outgrowth of the Glu/Asp-ergic cerebellar granule cells (Pearce et al., 1987). It has also been demonstrated that advancing growth cones release transmitters spontaneously (Humè et al., 1983) and have an active $\bar{H} A$ uptake of neurotransmitters (Gordon-Weeks et al., 1984). Therefore, the early appearance and avidity of HA uptake mechanisms, e.g., of D-Asp, may function to control neurite outgrowth and to inhibit precocious or ectopic establishment of synapseses by providing strict contrōol of extracellular neurotransmitter concentrations during devélopment.

Preliminary studies show that $\mathrm{KCl}$-evoked release of preloaded $\mathrm{D}^{-3} \mathrm{H}$-Asp and of endogenous Glu has not attained more than $70-80 \%$ of the adult capacity at PNW7 in either of the visual areas in the kitten brain (V. M. Fosse, unpublished observations). This is consistent with the notion that the complete functional development of synaptic junctions does not occur until some time after the initial establishment of synapses (see Wolff et al., 1984). There is now ample evidence for such temporal sequences of maturation at Glu/Asp-ergic synapses in the rat SC (Fosse et al., 1984b; V. M. Fosse, unpublished observations), at Glu/Asp-ergic synapses in cerebellum (Sandoval et al., 1984), GABAergic synapses in visual cortex (Kvale et al., 1983; Wolff et al., 1984), and forebrain (Redburn et al., 1978) and in cell cultures of striatal GABAergic neurons (Weiss et al., 1986).

\section{GABAergic systems \\ Areas 17 and 18}

Considerable experimental evidence suggests that a multitude of nonpyramidal cells, e.g., aspinous and sparsely spinous stellate cells and chandelier cells, within the visual cortex use GABA as neurotransmitter (see Houser et al., 1984). Several of the local GABAergic neurons may be involved in the generation of orientation selectivity and other characteristics (Houser et al., 1984; Sillito, 1984). The degree of orientation selectivity in Area 17 increases gradually over the first 5 postnatal weeks (Bonds, 1979; Albus and Wolf, 1984; Braastad and Heggelund, 1985) and appears to be nearly congruous with the postnatal changes of GAD activity in Areas 17 and 18 (Figs. 1, 2). Our findings are also in agreement with the development of cortical inhibition in kittens as observed with a slice preparation (Komatsu, 1983). We also found that the development of GAD paralleled the ontogeny of symmetric Type II synapses in kitten visual cortex (Winfield, 1981) in accordance with immunohistochemical evidence that many of the neurons/terminals that make such synapses are GABAergic (Ribak, 1978; Houser et al., 1984; Somogyi and Hodgson, 1985).

Although the density of Type II synapses (Winficld, 1981; Mates and Lund, 1983b) and GABA binding sites (Shaw et al., $1985,1986)$ exceed their respective adult levels in the postnatal period, this is not reflected as exuberant GAD activity in Areas 17 and 18 (Figs. 1, 2), in contrast to the nearly parallel changes in HA D-Asp uptake and Type I synapse density. Similarly, in rat visual cortex, LGN, and SC, the HA GABA uptake, but not GAD, exceeds the adult level in the early postnatal period (Kvale et al., 1983; Fosse et al., 1984b). It could be that a given neuron attains a certain maximal expression of transmitter synthesizing enzymes (e.g., GAD), which remains relatively constant after a certain developmental stage. Subsequently, one can envisage that the enzymes are redistributed to those terminals at which synapses become permanent and functional. There is evidence 
for this in sprouting cholinergic fibers of the superior cervical ganglion, i.e., expression of $\mathrm{ChAT}$ is not directly influenced by the degree of axonal branching in response to injury (Fonnum et al., 1984b). Also after chronic lesions of adult rât visual cortex the changes in GAD and ChAT activities are considerably less than those observed for HA D-Asp uptake subsequent to presumed sprouting of undamaged afferents and intrinsic neurons in SC (Fosse and Opstad, 1986).

\section{LGN and pulvinar}

GABA is a transmitter of local neurons in LGN and in afferents from the thalamic reticular nucleus (Houser et al., 1980; Fitzpatrick et al., 1984). The GABA-mediated inhibition has an important influence on response characteristics of the LGN neurons (Sillito and Kemp, 1983a; Berardi and Morrone, 1984). We found that GAD activity reached adult levels in PNW3 (Fig. 3). However, the inhibitory synapses (Winfield et al., 1976) and GABA-mediated inhibition mature in PNW6 subsequently to maturation of the excitatory inputs (Berardi and Morrone, 1984). These observations are in contrast to the concerted development of GAD, Type II synapse density, and GABA-mediated inhibition in the visual cortex. This discrepancy may indicate that other factors, e.g., maturity of corticofugal afferents (see Stein and Gallagher, 1981; Vidyasagar and Urbas, 1982), are of importance for functional development in the visual thalamus. Notably in adults thalamic functions are strongly influenced by afferents of cortical origin (Singer, 1977).

\section{Superior colliculus}

Intrinsic GABAergic neurons in the superficial layers of SC (Mize et al., 1982; Ottersen and Storm-Mathisen, 1984; Fosse and Fonnum, 1986) are probably involved in shaping receptive fields of, and conferring orientation selectivity to, other SC neurons (Stein and Gallagher, 1981). Most likely, the postnatal development of GAD in the visual part of SC (Fig. 5) reflects formation of the intrinsic inhibitory elements. The function and development of response characteristics in SC depends upon the effectiveness of the visual corticofugal afferents (Stein and Gallagher, 1981). Functional maturity of the latter is not apparent until after PNW3, which coincides with the decline of HA D-Asp uptake (Fig. 5) and the maturation of GAD activity.

GAD developed earlier in the nonvisual part of SC (Fig. 6) than in the superficial layers. This probably reflects an earlier synaptic development of the GABAergic afferents from substantia nigra (Vincent et al., 1978) and mesencephalic reticular formation (Araki et al., 1984) than at the terminals of intrinsic GABA neurons. This interpretation is supported by data showing an earlier neuron formation and proliferation in the deep layers than in the superficial strata (Brückner et al., 1976; Mustari et al., 1979). The laminar maturation of GAD in SC is similar to the developmental pattern of neurons in cerebral cortex (Rakic, 1984) and of GABAergic elements in the visual cortex (Miller, 1986).

The GABAergic elements in deep layers of SC influence several efferent systems that govern orientation behavior (Hikosaka and Wurtz, 1985; Meredith and Stein, 1985). We found that the GABAergic systems of the deep layers (Fig. 6) were nearly adult in newborn kittens. This agrees with the early development of tactile and auditory responses within deep layers of SC (Stein et al., 1973; Norton, 1974), where these responses are integrated (Wurtz and Albano, 1980).

\section{Cholinergic systems}

Wc observed biphasic developmental profiles for ChAT in Areas 17 and 18 (Figs, 1, 2). Similar profiles for ChAT and AChE in the cat visual cortex have been described previously (Potempska et al., 1979). The transient presence of near-adult ChAT activity in Areas 17 and 18 was intriguing and may reflect early postnatal neuronal transformations (Parnạvelàs and Edmunds, 1983) such as redistribution or a decrease in the number of cholinergic afferents (Shaw et al., 1984; Stichel and Singer; 1984), which occur before the onset of the critical period for visual cortical plasticity, i.e., $\overline{P N} \bar{W} 2-3$. Furthermore, transient AChE-containing neuronal cell bodies are present in the visual cortex during the early postnatal period (Bear et al., 1985). All of these changes could manifest themselves as the developmental profiles of mean cortical ChAT activity depicted in Figures 1 and 2 , and as observed previously by Potempska et al. (1979). The unique developmental profile of ChAT activity in areas 17 and 18 may be relevant to the suggested influence of cholinergic afferents on visual cortical plasticity (Sillito, 1983; Bear and Singer, 1986).

Terminals of cholinergic afferents from the basal forebrain (Vincent and Reiner, 1987) and some thalamic areas (Rieck and Carey, 1984) are the main location of cortical ChAT activity (Stichel and Singer, 1985). It has been suggested that ACh (Bear and Singer, 1986), in addition to noradrenaline (Kasamatsu and Pettigrew, 1979), has important roles in the regulation of cortical plasticity during the critical period. ACh facilitates excitatory transmission in striate cortex (Sillito, 1983; Bear and Singer, 1986) by increasing the probability of postsynaptic activation. The latter seems to be a prerequisite for cortical plasticity (Rauschecker and Singer, 1979; Kleinschmidt et al., 1987). Accordingly, one would predict increased cholinergic neurotransmission during the critical period. However, we actually found reduced ChAT activity in this period. Despite this, it could be that increased density or sensitivity of muscarinic receptors (Shaw et al., 1984, 1985, 1986) counteracts the apparently decreased ability for ACh synthesis.

ChAT exhibited an extremely slow development in LGN and pulvinar (Figs. 3 and 4). The slow ontogeny of ChAT in LGN has also been observed previously (Potempska et al., 1979). However, the functional significance of the protracted development of ChAT in the visual thalamus is difficult to assess. It is interesting to note, however, that the development of ChAT in the thalamus parallels the second phase of ChAT-development in the visual cortical areas.

The cholinergic afferents in SC originate in nucleus cuneiformis and the parabigeminal nucleus (Vincent and Reiner, 1987), and there is a denser cholinergic innervation of superficial than deeper layers in the adult SC (Fosse et al., 1984a; Vincent and Reiner, 1987). The latter is comparable with our observation that ChAT activity was more developed in the superficial than in the deeper (nonvisual) layers of SC in the first 2 postnatal weeks (Figs. 5 and 6). However, the laminar development of ChAT in SC contrasts the laminar shifts of cholinergic innervation of kitten visual cortex (Shaw et al., 1984, 1986; Stichel and Singer, 1985), as well as the sequence of neuron formation, synaptogenesis (Brückner et al., 1976; Mathers et al., 1978; Mustari et al., 1979), and the maturation of Glu/Asp-ergic and GABAergic systems within SC (Figs. 5, 6). These discrepancies are not easily fathomed. Nevertheless, our neurochemical find- 
ings regarding ChAT development in SC are supported by a similar laminar ontogeny of AChE (Harvey and MacDonald, 1985).

\section{Effects of dark-rearing on neurochemical development}

The basic responses of central neurons are provided by excitatory afferent connections that are sharpened, or fine-tuned, by intrinsic inhibitory connections, e.g., in the cat visual cortex (Murphy and Hirsch, 1982; Sillito, 1984). It has also been demonstrated that environmental factors, e.g., dark-rearing, may affect the proper development of cortical function (Wicscl, 1982). We found that dark-rearing from birth until PNW6 attenuated GAD development and conceivably GABAergic neurotransmission in Areas 17 and 18, as well as in the other visual areas (Table 2). Since orientation selectivity in striate cortex is under GABAergic control (Sillito, 1984), one could anticipate that the development of orientation selectivity was altered by dark-rearing. The physiological evidence for this is conflicting, however. Bonds (1979) reported that the normal increase of orientation selectivity did not occur during dark-rearing until PNW3-6, whereas Braastad and Heggelund (1985) found that orientation selectivity improved normally during the first 4 postnatal weeks despite dark-rearing. The rather modest reductions of GAD activity in Areas 17 and 18 (Table 2) tend to support the latter observation.

If the developmental profiles of neurochemical parameters are delayed during dark-rearing, one would predict from Figures 1-6 that GAD development was slightly delayed throughout the entire visual system. Similarly, one would predict that $\mathrm{ChAT}$ was slightly elevated only in Areas 17 and 18 . Thus, the effects observed experimentally after 6 weeks of dark-rearing (Table 2) agree with what could be predicted from such shifts and the suggested delay of the critical period during/after dark-rearing (Cynader and Mitchcll, 1980).

In neither of the visual areas was HA D-Asp uptake affected after neonatal dark-rearing (Table 2). This could be due to the very high uptake activity in the postnatal period, which would make it difficult to detect small changes. However, our negative findings regarding effects of dark-rearing on the Glu/Asp-ergic elements are in keeping with available electrophysiological data on development of kitlen visual cortex (Pettigrew, 1974; Leventhal and Hirsch, 1980).

One of the principal findings after neonatal dark-rearing is feeble responsivity of cortical neurons (Braastad and Heggelund, 1985). This stands in marked contrast to the equivocal effects of dark-rearing on development of orientation selectivity (Bonds, 1979; Braastad and Heggelund, 1985) and the relatively small effects on neurochemical parameters (Table 2; see also Sinha and Rose, 1976; Bigl and Biesold, 1978; Biesold et al., 1984; Schliebs et al., 1984). It is possible that changes in regulation of neurotransmitter release and postsynaptic activation (Kleinschmidt et al., 1987) or intracellular messenger systems are the main targets affected by environmental manipulations during critical stages of development. Hence, the basis for the rather dramatic electrophysiological changes observed after darkrearing (Wiesel, 1982) may, instead, be sought in subtle molecular processes in affected neurons and terminals/synapses rather than as gross changes in enzyme activities or receptor populations. Recent advances in molecular neurobiology will certainly facilitate the elucidation of mechanisms that influence neural specificity and function during development and the susceptibility to environmental manipulations.

\section{References}

Albus, K., and W. Wolf (1984) Early post-natal development of neuronal function in the kittens' visual cortex: $A$ laminar analysis. J. Physiol. (Lond.) 348: 153-185.

Anker, R. L. (1977) The prenatal development of some of the visual pathways in the cat. J. Comp. Neurol. 173: 185-204

Araki, M., P. L. McGeer, and E. G. McGeer (1984) Presumptive $\gamma=$ aminobutyric acid pathways from the midbrain to the superior colliculus studied by a combined horseradish peroxidase $-\gamma$-amino= butyric acid transaminase pharmacohistochemical method. Neuroscience $13: 433=439$.

Bader, C. R., R. W. Baughman, and J. L. Moore (1978) Different time course of development for high affinity choline uptake and choline acetyltransferase in the chick retina. Proc. Natl. Acad. Sci. USA 75: $2525-2529$.

Baughman, R. W., and C. D. Gilbert (1981) Aspartate and glutamate as possible neurotransmitters in the visual cortex. J. Neurosci. 1:427439.

Bear, M. F., and W. Singer (1986) Modulation of visual cortical plasticity by acetylcholine and noradrenalin. Nature 320: 172-176.

Bear, M. F., K. M. Carnes, and F. F. Ebner (1985) Postnatal changes in the distribution of acetylcholinesterase in kitten striate cortex. J. Comp. Neurol. 237: 519-532.

Berardi, N., and M. C. Morrone (1984) Development of $\gamma$-aminobutyric acid mediated inhibition of X-cells of the cat lateral geniculate nucleus. J. Physiol. (Lond.) 357: 525-537.

Biesold, D., R. Schliebs, T. Rothe, M. Aurich, E. Ungewitter, and V. Bigl (1984) Effect of visual deprivation on development of mediator receptors in the rat visual system. Nevrofiziol. 16:691-701 (in Russian).

Bigl, V., and D. Biesold (1978) Sensory deprivation and brain development. In Proceedings of the European Society of Neurochemistry, Bd. 1, V. Neuhoff, ed., pp. 199-215, Verlag Chemie, Weinheim.

Bonds, A. B. (1979) Development of orientation tuning in the visual cortex of kittens. In Developmental Neurobiology of Vision, R. D. Freeman, ed., pp. 31-41, Plenum, New York.

Braastad, B. O., and P. Heggelund (1985) Development of spatial receptive field organization and orientation selectivity in kitten striate cortex. J. Ncurophysiol 53: 1158-1178.

Brodmann, K. (1905) Beitrage zur histologischen lokalisation der grosshirnrinde: Die rindenfelder der niederen affen. J. Psychol. Neurol. (Leipz.) 4: 177-226.

Brückner, G., V. Mares, and D. Biesold (1976) Neurogenesis in the visual system of the rat. An autoradiographic investigation. J. Comp. Neurol. 166: 245-256.

Coyle, J. T., and J. S. Enna (1976) Neurochemical aspects of the ontogenesis of GABAergic neurons in the rat brain. Brain Res. 111: 119-133.

Cragg, B. G. (1975) The development of synapses in the visual system of the cat. J. Comp. Neurol. 160: 147-166.

Cynader, M., and D. E. Mitchell (1980) Prolonged sensitivity to monocular deprivation in dark reared cats. J. Neurophysiol. 43: 10261040.

Dames, W., F. Joo, O. Feher, J. Toldi, and J. R. Wolff (1985) $\gamma$-Aminobutyric acid enables synaptogenesis in the intact superior cervical ganglion of the adult rat. Neurosci. Lett. 54: 159-164.

Eitschberger, E. (1970) Entwicklung und chemodifferenzierung des thalamus der ratte. Erg. Anat. Entw. Gesch. 42: 1-73.

Fagg, G. E., T. H. Lanthorn, A. C. Foster, L. Maier, J. Dingwall, J. D. Lane, and A. Matus (1986) Discrimination of excitatory amino acid receptor sub-types using radioligand binding techniques. In Excitatory Amino Acids, P. J. Roberts, J. Storm-Mathisen, and H. F. Bradford, eds., pp. 263-277, Macmillan, London.

Ferrero, P., A. Guidotti, and E. Costa (1984) Increase in the $B_{\max }$ of $\gamma$-aminobutyric acid-A recognition sites in brain regions of mice receiving diazepam. Proc. Natl. Acad. Sci. USA 81: 2247-2251.

Fitzpatrick, D., G. R. Penny, and D. E. Schmechcl (1984) Glutamic acid decarboxylase-immunoreactive neurons and terminals in the lateral geniculate nucleus of the cat. J. Neurosci. 4: 1809-1829.

Fonnum, F. (1984) Glutamate: A transmitter in mammalian brain. J. Neurochem. 42: 1-11. 
Fonnum, F., and D. Malthe-Sørenssen (1981) Identification of glutamergic neurons. In Glutamate. Transmitter in the Central Nervous System, P. J. Roberts, J. Storm-Mathisen, and G. A. R. Johnston, eds., pp. 205-221, Wiley, New York.

Fonnum, F., R. Lund Karlsen, D. Malthe-Sorenssen, S. Sterri, and I. Walaas (1980) High affinity transport systems and their role in transmitter action. In The Cell Surface and Neuronal Function, C. W. Cotman, G. Postc, and G. L. Nichols, cds., pp. 455-504, Elsevier, Amsterdam.

Fonnum, F., V. M. Fosse, and C. N. Allen (1984a) Identification of excitatory amino acid pathways in the mammalian nervous system. In Excitotoxins, K. Fuxe, P. J. Roberts, and R. Schwarcz, eds., pp. 3-18, Plenum, New York.

Fonnum, F., J. Mæhlen, and A. Njả (1984b) Functional, structural and chemical correlates of sprouting of intact preganglionic sympathetic axons in the guinea pig. J. Physiol. (Lond.) 347: 741-749.

Fosse, V. M., and F. Fonnum (1986) Effects of kainic acid, and other excitotoxins, in the rat superior colliculus: Relations to glutamatergic afferents. Brain Res. 383: 28-37.

Fosse, V. M., and F. Fonnum (1987) Biochemical evidence for glutamate and/or aspartate as neurotransmitter(s) in fibers from the visual cortex to the lateral posterior thalamic nucleus (pulvinar) in rats. Brain Res. 400: 219-224.

Fosse, V. M., and P. K. Opstad (1986) Biochemical plasticity in the superior colliculus of adult rats after chronic visual cortex ablation. Brain Res. 372: 189-192.

Fosse, V. M., P. Heggelund, E. Iversen, and F. Fonnum (1984a) Effects of Area 17 ablation on neurotransmitter parameters in efferents to Area 18, the lateral geniculate body, pulvinar and superior colliculus in the cat. Neurosci. Lett. 52: 323-328.

Fosse, V. M., I. Kvale, R. Lund Karlsen, and F. Fonnum (1984b) Postnatal neurochemical development of the rat visual system. In Organizing Principles of Neural Development, S. C. Sharma, ed., pp. 187-203, Plenum, New York.

Fosse, V. M., J. Kolstad, and F. Fonnum (1986) A bioluminescence method for the measurement of L-glutamate: Applications to the study of changes in the release of L-glutamate from lateral geniculate nucleus and superior colliculus after visual cortex ablation in rats. $J$. Neurochem. 47: 340-349.

Foster, A. C., and G. E. Fagg (1984) $\Lambda$ cidic amino acid binding sites in mammalian neuronal membranes: Their characteristics and relationship to synaptic receptors. Brain Res. Rev. 7: 103-164.

Gilbert, C. D., and T. N. Wiesel (1979) Morphology and intracortical projections of functionally characterized neurons in the cat visual cortex. Nature 280: 120-125.

Gordon-Weeks, P. R., R. O. Lockerbie, and B. R. Pearce (1984) Uptake and release of $\left[{ }^{3} \mathrm{H}\right] \mathrm{GABA}$ by growth cones isolated from neonatal rat brain. Neurosci. Lett. 52: 205-210.

Greenamayre, J. T., A. B. Young, and J. B. Penney (1984) Quantitative autoradiographic distribution of $\mathrm{L}-\left[{ }^{3} \mathrm{H}\right]$ glutamate-binding sites in rat central nervous system. J. Neurosci. 4: 2133-2144.

Harvey, A. R., and A. M. McDonald (1985) The development of acetylcholinesterase activity in normal and transplanted superior colliculus. J. Comp. Neurol. 240: 117-127.

Haydon, P. G., D. P. McCobb, and S. B. Kater (1984) Serotonin selectively inhibits growth cone motility and synaptogenesis of specific identified neurons. Science 226: 561-564.

Hikosaka, O., and R. H. Wurtz (1985) Modification of saccadic eye movements by GABA-related substances. I. Effect of muscimol and bicuculline in monkey superior colliculus. J. Neurophysiol. 53: 266291.

Hitzemann, R. J., and H. H. Loh (1978) High affinity GABA and glutamate transport in developing nerve ending particles. Brain Res. 159: $29-40$

Houser, C. R., J. F. Vaughn, R. P. Barber, and E. Roberts (1980) GABA neurons are the major cell type of the nucleus reticularis thalami. Brain Res. 200: 341-345.

Houser, C. R., J. E. Vaughn, S. H. C. Hendry, E. G. Jones, and A. Peters (1984) GABA neurons in the cerebral cortex. In Cerebral Cortex, Vol. 2, Functional Properties of Cortical Cells, E. G. Jones and A. Peters, eds., pp. 63-89, Academic, New York.

Hume, R. I., L. W. Role, and G. D. Fischbach (1983) Acetylcholine release from growth cones detected with patches of acetylcholine receptor-rich membranes. Nature 305: 632-634.

Jones, E. G. (1983) The thalamus. In Chemical Neuroanatomy, P. C. Emson, ed., pp. 257-293, Raven, New York.
Jonsson, G., and T. Kasamatsu (1983) Maturation of monoaminc ncurotransmitters and receptors in cat occipital cortex during postnatal sritical pcriod. Exp. Brain Res. 50: 449-458.

Kalil, R. E., M. W. Dubin, G. Scott, and L. A. Stark (1986) Elimination of action potentials blocks the structural development of retinogeniculate synapses. Nature 323: 156-158.

Kasamatsu, T., and J. D. Pettigrew (1979) Preservation of binocularity after monocular deprivation in the striate cortex of kittens treated with 6-hydroxydopamine. J. Comp. Neurol. 185: 139-162.

Kleinschmidt, A., M. F. Bear, and W. Singer (1987) Blockade of "NMDA" reccptors disrupts experience-dependent plasticity of kitten striate cortex. Science 238: 355-358.

Komatsu, Y. (1983) Development of cortical inhibition in kitten striate cortex investigated by a slice preparation. Dev. Brain Res. 8: 136139.

Kvale, I., V. M. Fosse, and F. Fonnum (1983) Development of neurotransmitter parameters in lateral geniculate body, superior colliculus and visual cortex of the albino rat. Dev. Brain Res. 7: 137-145.

Labriola, A. R., and L. K. Laemle (1977) Cellular morphology in the visual layer of the developing rat superior colliculus. Exp. Neurol. 55: $247-268$

Leventhal, A. G., and R. K. Hirsch (1980) Receptive-field properties of different classes of neurons in visual cortex of normal and darkreared cats. J. Neurophysiol. 43: 1111-1132.

Lund Karlsen, R., and F. Fonnum (1978) Evidence for glutamate as a neurotransmitter in the corticofugal fibers to the dorsal lateral geniculate body and the superior colliculus in rats. Brain Res. 151:457467.

Mason, C. A. (1983) Postnatal maturation of neurons in the cats' lateral geniculate nucleus. J. Comp. Neurol. 217: 458-469.

Mates, S. L., and J. S. Lund (1983a) Spine formation and maturation of Type I synapses on spiny stellate neurons in primate visual cortex. J. Comp. Neurol. 221: 91-97.

Mates, S. L., and J. S. Lund (1983b) Developmental changes in the relationship between Type 2 synapses and spiny neurons in the monkey visual cortex. J. Comp. Neurol. 221: 98-105.

Mathers, L. H., Jr. (1977) Postnatal maturation of neurons in the rabbit superior colliculus. J. Comp. Neurol. 173: 439-456.

Mathers, L. H., Jr., K. L. Mercer, and P. E. Marshall (1978) Synaptic development in the rabbit superior colliculus and visual cortex. Exp. Brain Res. 33: 353-369.

McDonald, J. K., S. G. Speciale, and J. G. Parnavelas (1981) The development of glutamic acid decarboxylase in the visual cortex and the dorsal lateral geniculate nucleus of the rat. Brain Res. 217:364 367.

Meredith, M. A., and B. E. Stein (1985) Descending efferents from the superior colliculus relay integrated multisensory information. Science 227: 657-659.

Meyer, G., and R. Ferres-Torres (1984) Postnatal maturation of nonpyramidal neurons in the visual cortex of the cat. J. Comp. Neurol. 228: 226-244

Miller, M.W. (1986) The migration and neurochemical differentiation of $\gamma$-aminobutyric acid (GABA)-immunoreactive neurons in rat visual cortex as demonstrated by a combined immunocytochemicalautoradiographic technique. Dev. Brain Res. 28: 41-46.

Mize, R. R., R. F. Spencer, and P. Sterling (1982) Two types of GABAaccumulating neurons in the superficial grey layer of the cat superior colliculus. J. Comp. Neurol. 206: 180-192.

Murphy, R. K., and H. V. B. Hirsch (1982) From cat to cricket: The genesis of response selectivity of interneurons. Curr. Topics Dev. Biol. 17: $241-256$

Mustari, M. J., R. D. Lund, and K. Graubard (1979) Histogenesis of the superior colliculus of the albino rat: A tritiated thymidine study. Brian Res. 164: 39-52.

Norton, T. T. (1974) Receptive-field properties of superior colliculus cells and development of visual behavior in kittens. J. Neurophysiol. 37: 674-690.

Ogren, M. P., and P. Rakic (1981) The prenatal development of the pulvinar in the monkey: ${ }^{3} \mathrm{H}$-thymidine autoradiographic and morphometric analyses. Anat. Embryol. 162: 1-20.

Ottersen, O. P., and J. Storm-Mathisen (1984) Ncurons containing or accumulating transmitter amino acids. In Handbook of Chemical Neuroanatomy, Vol. 3: Classical Transmitters and Transmitter Receptors in the CNS, Part II, A. Björklund, T. Hökfelt, and M. J. Kuhar, eds., pp. 141-246, Elsevier, Amsterdam.

Parnavelas, J. G. (1984) Physiological properties of identified neurons. 
In Cerebral Cortex, Vol. 2, Functional Propeties of Cortical Cells, E. G. Jones and A. Peters, eds., pp. 205-239, Academic, New York.

Parnavelas, J. G., and S. M. Edmunds (1983) Further evidence that Retzius-Cajal cells transform to nonpyramidal neurons in the developing rat visual cortex. J. Ncurocytol. 12: 863-871.

Pearce, I. A., M. A. Cambray-Deakin, and R. D. Burgoyne (1987) Glutamate acting on NMDA receptors stimulates neurite outgrowth from cercbellat granule cells. FEBS Lett. 223: 143-147.

Pettigrew, J. D. (1974) The effect of visual experience on the development of stimulus specificity by kitten cortical neurons. J. Physiol. (Lond.) 237: 49-74.

Potempska, A., J. Skangiel-Kramska, and M. Kossut (1979) Development of cholinergic enzymes and adenosine triphosphatase activity of optic system of cats in normal and restricted visual input conditions. Dev. Neúrosci. 2: 38-45.

Rakic, P. (1984) Organizing principles for development of primate cerebral cortex. In Organizing Principles of Neural Development, S. C. Sharma, ed., pp. 21-48, Plenum, New York.

Rauschecker, J. P., and W. Singer (1979) Changes in the circuitry of the kitten visual cortex are gated by postsynaptic activity. Nature 280 : $58-60$.

Redburn, D. A., D. Broome, J. Ferkany, and S. J. Enna (1978) Development of rat brain uptake and calcium-dependent release of GABA. Brain Res. 152: 511-519.

Reinoso-Suarez, F. (1961) Topografischer Hirnatlas der Katze für experimental-physiologische Untersuchungen, E. Merck A. G., Darmstadt, FRG.

Ribak, C. E. (1978) Aspinous and sparsely-spinous stellate neurons in the visual cortex of rats contain glutamic acid decarboxylase. J. Neurocytol. 7: 461-478.

Rieck, R., and R. G. Carey (1984) Evidence for a laminar organization of basal forebrain afferents to the visual cortex. Brain Res. 297: 374380.

Sandoval, M.-E., C. A. Torner, and L. Medrano (1984) High affinity uptake and $\mathrm{Ca}^{2+}$-dependent release of glutamic acid in the developing cerebellum. Neuroscience 11: 867-875.

Schliebs, R., E. Kunert, and V. Bigl (1984) Effect of monocular deprivation on uptake and binding of $\left[{ }^{3} \mathrm{H}\right]$ glutamate in the visual system of rat brain. J. Neurochem. 43: 1490-1493.

Shaw, C., M. C. Needler, and M. Cynader (1984) Ontogenesis of muscarinic acetylcholine binding sites in cat visual cortex: Reversal of specific laminar distribution during the critical period. Dev. Brain Res. 14: 295-299.

Shaw, C., M. C. Needler, M. Wilkinson, C. Aoki, and M. Cynader (1985) Modification of neurotransmitter sensitivity in cat visual cortex during the critical period. Dev. Brain Res. 22: 67-73.

Shaw, C., M. Wilkinson, M. Cynader, M. C. Needler, C. Aoki, and S. E. Hall (1986) The laminar distributions and postnatal development of neurotransmitter and neuromodulator receptors in cat visual cortex. Brain Res. Bull. 16: 661-671.

Sillito, A. M. (1983) Plasticity in the visual cortex. Nature 303: 477478.

Sillito, A. M. (1984) Functional considerations of the operation of GABAergic inhibitory processes in the visual cortex. In Cerebral Cortex, Vol. 2, Functional Properties of Cortical Cells, E. G. Jones and A. Peters, eds., pp. 91-117, Academic, New York.

Sillito, A. M., and J. A. Kcmp (1983a) The influence of GABAergic inhibitory processes on the receptive field structure of $\mathrm{X}$ and $\mathrm{Y}$ cells in cat dorsal lateral geniculate nucleus (dLGN). Brain Res. 277: 6377.

Sillito, A. M., and J. A. Kemp (1983b) Cholinergic modulation of the functional organization of the cat visual cortex. Brain Res. 289: 143155.

Singer, W. (1977) Control of thalamic transmission by corticofugal and ascending reticular pathways in the visual system. Physiol. Rev. 57: $386-420$.

Sinha, A. K., and S. P. R. Rose (1976) Dark rearing and visual stim- ulation in the rat: Effect on brain enzymes. J. Neurochem. 27:921926.

Somogyi, P., and A. J. Hodgson (1985) Antiserum to $\gamma$-aminobutyric acid: III. Demonstration of GABA in Golgi-impregnated neurons and in conventional electron microscopic sections of cat striate cortex. J. Histochem. Cytochem. 33: 249-257.

Stein, B. E., and H. L. Gallagher (1981) Maturation of cortical control over superior colliculus cells in cat. Brain Res. 223: 429-435.

Stcin, B. E., E. Labos, and L. Kruger (1973) Sequence of changes in properties of neurons of superior colliculus of the kitten during maturation. J. Neurophysiol. 36: 667-679.

Stichel, C. C., and W. Singer (1984) Organization of cholinergic fibers in the visual system of kittens and adult cats. Neurosci. Lett. (Suppl.) 18: $\$ 67$.

Stichel, C. C., and W. Singer (1985) Organization and morphological characteristics of choline acetyltransferase-containing fibers in the visual thalamus of the cat. Neurosci. Lett. 53: 155-160.

Storm-Mathisen, J. (1977) Localization of transmitter candidates in the brain: The hippocampal formation as a model. Prog. Neurobiol. 8: 119-181.

Streit, P. (1984) Glutamate and aspartate as transmitter candidates for systems of cerebral cortex. In Cerebral Cortex, Vol. 2, Functional Properties of Cortical Cells, E. G. Jones and A. Peters, eds., pp. 119 143, Academic, New York.

Thompson, J. M. (1982) Increase in acetylcholine release from chick embryo retina during development. Dev. Brain Res. 4: 259-264.

Tsumoto, T., H. Masui, and H. Sato (1986) Excitatory amino acid transmitters in neuronal circuits of the cat visual cortex. J. Neurophysiol. 55: 469-483.

Vidyasagar, T. R., and J. V. Urbas (1982) Orientation sensitivity of cat LGN neurons with and without inputs from visual cortical areas 17 and 18. Exp. Brain Res. 46: 157-169.

Vincent, S. R., and E. G. McGeer (1980) A comparison of sodiumdependent glutamate binding with high-affinity glutamate uptake in rat striatum. Brain Res. 184: 99-108.

Vincent, S. R., and P. R. Reiner (1987) The immunohistochemical localization of choline acetyltransferase in the cat brain. Brain Res. Bull. 18: 371-415.

Vincent, S. R., T. Hattori, and E. G. McGeer (1978) The nigrotectal projection: A biochemical and ultrastructural organization. Brain Res. 151: $159-164$.

Waniewski, R. A., and D. L. Martin (1983) Selective inhibition of glial versus neuronal uptake of L-glutamic acid by SITS. Brain Res. 268: 390-394.

Weiss, S., J.-P. Pin, M. Sebben, D. E. Kemp, F. Sladeczek, J. Gabrion, and J. Bockaert (1986) Synaptogenesis of cultured striatal neurons in serum-free medium: A morphological and biochemical study. Proc. Natl. Acad. Sci. USA 83: 2238-2242.

Wiesel, T. N. (1982) Postnatal development of the visual cortex and the influence of environment. Nature 299: 583-591.

Winfield, D. A. (1981) The postnatal development of synapses in the visual cortex of the cat and the effects of eyelid closure. Brain Res. 206: 166-171.

Winfield, D. A., M. P. Headon, and T. P. S. Powell (1976) Postnatal development of the synaptic organization of the lateral geniculate nucleus in the kitten with unilateral eyelid suture. Nature 263: 591594.

Wolff, J. R. (1979) Hinweise auf eine doppelrolle von GABA als synaptische transmitter und als morphogenetischer faktor. Verh. Dtsch. Zool. Ges. 72: 194-200.

Wolff, J. R., V. J. Balcar, T. Zetzsche, H. Böttcher, D. E. Schmechel, and B. M. Cronwall (1984) Development of GABAergic system in rat visual cortex. Adv. Exp. Med. 181: 215-239.

Wurtz, R. H., and J. E. Albano (1980) Visual motor function of the primate superior colliculus. Annu. Rev. Neurosci. 3: 189-226.

Zilles, K. J. (1978) Ontogenesis of the visual system. Adv. Anat. Embryol. Cell Biol. 54 (fasc. 3): 138 pp. 